\title{
Editorial: Innovative Methodologies for Resilient Buildings and Cities
}

\author{
Izuru Takewaki ${ }^{1 \star}$, Masayuki Kohiyama ${ }^{2}$, Tomaso Trombetti ${ }^{3}$, Solomon Tesfamariam ${ }^{4}$ and \\ Xinzheng $L u^{5}$ \\ ${ }^{1}$ Department of Architecture and Architectural Engineering, Kyoto University, Kyoto, Japan, ${ }^{2}$ Department of System Design \\ Engineering, Keio University, Yokohama, Japan, ${ }^{3}$ Department of Civil, Chemical, Environmental and Materials Engineering, \\ University of Bologna, Bologna, Italy, ${ }^{4}$ Faculty of Applied Science, University of British Columbia, Okanagan, BC, Canada, \\ ${ }^{5}$ Department of Civil Engineering, Tsinghua University, Beijing, China
}

Keywords: resilience, robustness, earthquake risk, structural control, monitoring

\section{Editorial on the Research Topic}

\section{Innovative Methodologies for Resilient Buildings and Cities}

\section{OPEN ACCESS}

Edited by:

Andrea Belleri,

University of Bergamo, Italy

Reviewed by:

Andre R. Barbosa,

Oregon State University, United States

*Correspondence:

Izuru Takewaki

takewaki@archi.kyoto-u.ac.jp

Specialty section:

This article was submitted to

Earthquake Engineering,

a section of the journal

Frontiers in Built Environment

Received: 06 May 2019

Accepted: 28 June 2019

Published: 12 July 2019

Citation:

Takewaki I, Kohiyama M, Trombetti T,

Tesfamariam S and LuX (2019)

Editorial: Innovative Methodologies for Resilient Buildings and Cities.

Front. Built Environ. 5:94.

doi: 10.3389/fbuil.2019.00094
Resilient buildings and cities are in the center of common interests in modern academic communities for science and engineering related to built environment. Resilience of buildings and cities against multidisciplinary risks, e.g., earthquakes, strong winds, floods, etc., is strongly related to the sustainability of buildings and cities in which reduction of damage during a disaster and fast recovery from the damage are key issues. The reduction of damage is related to the level of resistance of buildings and the time of recovery is affected by the amount of supply of damaged members, assurance of restoration work, etc. Robustness, redundancy, resourcefulness, and rapidity are four key factors for supporting the full realization of design and construction of resilient buildings and cities. This Research Topic gathers cutting-edge and innovative research from various aspects, e.g., robustness of buildings and cities against earthquake risk, structural control and base-isolation for controlling damage risks, quantification of resilience measures, structural health monitoring, innovative structural engineering techniques for higher safety of buildings, resilience actions and tools at the urban scale, etc. After a detailed review, the following eight papers have been published in this Research Topic, i.e., collapse risk assessment of reinforced-concrete buildings, robustness evaluation of building structures considering the whole generation process of earthquake ground motions, multi-hazard prevention and mitigation in building structures, robustness evaluation of building structures with long natural period, optimal viscous damper placement for elastic-plastic structures subjected to the critical double impulse, proposal of configurations in concentrically steel braced frame, deformability of pipes in buildings as non-structural members, assessment of seismic vulnerability of buildings at regional scale.

In the first paper, Noh and Tesfamariam present the risk assessment for collapse of reinforced concrete moment resisting frame (RC MRF) buildings located in Vancouver, Canada which were designed in compliance with the building code. They investigate three- and six-story RC MRF building systems that include unreinforced masonry infill walls by comparing with those without such infill walls. These building systems represent low- to mid-rise structures. They conduct incremental dynamic analysis and develop the seismic fragility curves. Then mean annual frequency of collapse is evaluated via a sophisticated combination of fragility curves and hazard curves. It is shown that the bare RC buildings without infill wall are not sufficiently resistant to collapse to earthquakes in the case that the number of stories increases. Furthermore, it is demonstrated that the URM infill walls are apt to influence the behavior of the framed structure to collapse. It may be important to investigate not only the collapse risk of building structures but also the detailed behavior to collapse when developing earthquake-resisting systems for upgrading the earthquake resilience. 
In the second paper, Makita et al. focus on the robustness evaluation under the detailed consideration of the process of theoretical ground motion generation. In the process of theoretical ground motion generation, three stages are taken into account, i.e., (i) the process of fault rupture, (ii) the characteristics of wave propagation from the fault to the earthquake bedrock, (iii) the site amplification above the earthquake bedrock. They investigate the uncertainty in the fault rupture slip (slip distribution and rupture front). The process of wave propagation from the fault to the earthquake bedrock is expressed by the stochastic Green's function method in which the Fourier amplitude of the ground motion at the earthquake bedrock from a fault element is represented by Boore's model and the phase angle is modeled by the phase difference method. The robustness for the uncertain fault rupture slip and the uncertain fault rupture front is evaluated seen to play a key role for resilient building design. Since the critical ground motion produces the most detrimental building response among possible scenarios, it is expected that the proposed method can be a reliable tool for use in resilient building design.

In the third paper, Lin et al. present a research on multihazard prevention and mitigation in building structures which is of much interest in the civil engineering field. They propose an analytical model that facilitates to calculate the structural resistance of a type of multi-hazard resilient prefabricated concrete (MHRPC) frame which is subjected to simulated earthquake ground motions and subject to scenarios of column removal. The MHRPC frame consists of unbonded posttensioning (PT) tendons, energy-dissipating steel angles, and large rotational shear plates in addition to prefabricated RC beams and columns. Through a set of laboratory experiments, it is shown that the MHRPC frame exhibits low damage features and possesses self-centering properties of under seismic loading. On the other hand, when subjected to scenarios of column removal, the MHRPC frame is proven to possess high resistance against progressive collapse. It is concluded that this paper provides useful data for the design of MHRPC frame structures which are primarily designed for earthquake and progressive collapse. It seems important to take into account the concept of multi-hazard prevention and mitigation to enable the development of structural design methods for more robust and resilient reinforced concrete building structures.

In the fourth paper, Makita et al. focus on the use of the threedimensional finite difference method (3DFDM) for generation of simulated ground motions with rather long periods. The 3DFDM is taken advantage for capturing the critical ground motion which should be considered in the design stage of structures with a rather long natural period. Since it is understood that the 3DFDM is usually time-consuming, its use in a simple sensitivity algorithm is not preferred. This is because an independent response sensitivity is to be calculated for many design parameters. To remedy this problem, the authors introduce the method of bi-cubic spline interpolation for uncertain parameter distributions (seismic moment distribution). Then the response surface method is used effectively for predicting the response surface approximately from some sampling points. The authors treat the fault rupture slip distribution described in terms of seismic moments as an uncertainty parameter. It is shown that the most critical ground motion for structures with a rather long natural period can be captured by the proposed method in an effective manner. It seems desirable to take into account the whole system of ground motion generation with a certain level of accuracy in order to develop a resilient structural design method of buildings for unpredictable earthquake occurrence.

In the fifth paper, Akehashi and Takewaki propose a new method for optimal viscous damper placement for elastic-plastic multi-degree-of-freedom (MDOF) structures subjected to the critical double impulse as a representative of near-fault ground motions. The quantities in terms of the maximum interstory drift along the building height and the sum of the maximum interstory drifts in all stories are selected as the objective function and constraint. The corresponding optimization algorithm is investigated in which time-history response analyses and sensitivity analysis are effectively used. A novel concept of double impulse pushover (DIP) is proposed for determining the input velocity level of the critical double impulse. It is demonstrated that the combination of two algorithms, one for effective reduction of the overflowed maximum interstory drift via the concentrated allocation of dampers and the other for effective allocation of dampers via the use of a stable objective function, is effective for finding a stable optimal damper placement. It seems that the optimal damper placement, i.e., effective and efficient use of damper materials, leads to the design of controlled building structures with increased robustness, redundancy, and resilience.

In the sixth paper, Yang et al. investigate the concentrically braced frame $(\mathrm{CBF})$ which is a prevalent earthquake resistant system. While concentric braces have large stiffness, the check of buckling is important in its use. Several configurations of these bracing systems are proposed for different building codes available worldwide. These codes require the satisfaction of some details in the structural members and connections. However, it is true that there is no guidance in the selection of the best bracing configuration for design. The authors systematically examine the effect of the bracing configuration on the seismic response of a five-story prototype office building located in Vancouver, Canada. The authors design five different bracing configurations and investigate the candidates which follow the National Building Code of Canada and CSA S16 standard. They conduct the structural analysis in detail and systematically compare structural responses, initial costs, and life-cycle costs of the prototype building with five different bracing configurations. They derive the results that the different bracing configurations lead to different results in sizing the structural members. It seems that this result affects the initial material usage and the overall lifecycle cost of the building. It appears that the appropriate selection of bracing configuration leads to a reliable structural design of buildings with larger resilience.

In the seventh paper, Wang et al. study the pipes of a diameter of $150 \mathrm{~mm}$ (called DN150) which are often connected by grooved fit joints and employed as the stem pipelines. They enable to convey water vertically to different building stories and distribute them horizontally to different rooms. They are usually called the non-structural members which do not contribute to the structural safety for disturbances, but may influence significantly 
the functionality of buildings. Large deformability is needed in the grooved fit joints to allow the deformation between adjacent stories during an earthquake. The grooved fit joint can be improved by introducing a wider groove which enables the achievement of such large deformability. However, the authors claim that its seismic performance has never been thoroughly studied yet. This study conducted quasi-static tests on 12 DN150 grooved fit joints, including four elbow joints and eight DN150DN80 Tee joints. The mechanical behavior, rotational capacity and failure mode were examined and discussed. Finally, seismic fragility analysis of DN150 stem pipeline system in a 10-story building is conducted. It is demonstrated that the improved joints are sufficiently resistant for the maximum plausible earthquake ground motion and the leakage can be prevented in a reliable manner. It seems that the non-structural elements are important to assure the resilience of buildings in view of the business continuity.

In the eighth paper, Diana et al. explain that assessing seismic vulnerability at large scales requires accurate attribution of individual buildings to more general typological classes that are representative of the seismic behavior of the buildings sharing the same attributes. One-by-one evaluation of all buildings is a process of requiring long time and a lot of cost. It is shown that detailed individual evaluations are only suitable for important buildings, such as hospitals and other buildings, which play a central and emergent role in the post-earthquake phase. For other ordinary buildings, more simplified approaches seem sufficient. The central issues for reliable seismic assessment at large scales are to define a taxonomy that contains the most widespread typological classes as well as performing the attribution of the appropriate class to each building. The authors explain that a fast and accurate survey process is needed to attribute a correct class to each building which composes the urban system. The authors use the association-rule learning (ARL) to find links between building attributes and typological classes. They evaluate the accuracy of wide spreading these links learned on $<250$ buildings of a specific district in terms of class attribution and seismic vulnerability prediction. They make it clear that the time required to provide seismic vulnerability scenarios at city scale is significantly reduced, while accuracy is reduced by $<5 \%$. The authors enable this by considering only three attributes available on public databases (i.e., period of construction, number of floors, and shape of the roof). It seems important to assess the seismic vulnerability of buildings at regional scales by conducting the definition of the accurate attribution of individual buildings to more general typological classes that are representative of the seismic behavior of the buildings with the same attributes. This enables a reliable achievement of the construction of resilient buildings with less vulnerability.

\section{AUTHOR CONTRIBUTIONS}

All authors listed have made a substantial, direct and intellectual contribution to the work, and approved it for publication.

Conflict of Interest Statement: The authors declare that the research was conducted in the absence of any commercial or financial relationships that could be construed as a potential conflict of interest.

Copyright $\odot 2019$ Takewaki, Kohiyama, Trombetti, Tesfamariam and Lu. This is an open-access article distributed under the terms of the Creative Commons Attribution License (CC BY). The use, distribution or reproduction in other forums is permitted, provided the original author(s) and the copyright owner(s) are credited and that the original publication in this journal is cited, in accordance with accepted academic practice. No use, distribution or reproduction is permitted which does not comply with these terms. 